\title{
QUALIDADE FISIOLÓGICA DE SEMENTES DE ALGODOEIRO SUBMETIDAS A TRATAMENTOS QUÍMICO E BIOLÓGICO' ${ }^{1}$
}

\author{
AKEMI YARA KUROYANAGI FARIA², MARIA CRISTINA DE F. E ALBUQUERQUE ${ }^{3}$, DANIEL CASSETARI NETO4
}

\begin{abstract}
RESUMO - Uma alternativa aos tratamentos químicos de sementes é o uso de bioprotetores, por meio da microbiolização e, dentre esses, Trichoderma spp. têm sido considerados eficientes no controle de fungos e bactérias. Este trabalho foi conduzido com o objetivo de avaliar a eficiência dos tratamentos de sementes de algodoeiro com os fungicidas carboxin+thiram, carbendazin+thiram e flutolanil, comparando-os com Trichoderma harzianum, na germinação, no vigor das sementes e na promoção de crescimento das plântulas. Foram utilizadas sementes deslintadas de algodoeiro, da cultivar ITA 90, produzidas na safra de 1999/2000 e naturalmente infectadas. As sementes foram tratadas com suspensão de conídios de T. harzianum $\left(10 \times 10^{5}\right.$ conídios $\left./ \mathrm{mL}\right)$, com carboxin+thiram (140g i.a. + 140g i.a./100kg), com carbendazin+thiram (75g i.a.+175g i.a./100kg) e com flutolanil ( $100 \mathrm{~g}$ i.a. $/ 100 \mathrm{~kg})$. O isolado de T. harzianum utilizado na microbiolização foi o mais eficiente obtido em uma seleção realizada em sementes de algodoeiro produzidas no município de Campo Verde, MT. Avaliaram-se a germinação padrão, as emergências em areia e em campo, a germinação à baixa temperatura, o índice de velocidade de germinação, o índice de doença, a massa seca e o comprimento da parte aérea das plântulas oriundas de sementes, com e sem tratamento. Sementes tratadas com T. harzianum, carbendazin+thiram e carboxin+thiram apresentaram porcentagens de germinação e emergência mais elevadas e os dois primeiros proporcionaram também a emergência de plântulas mais vigorosas. Sementes tratadas com carboxin+thiram originaram plântulas menores e com menor massa seca.
\end{abstract}

Termos para indexação: algodão, vigor, Trichoderma harzianum, fungicidas.

\section{PHYSIOLOGICAL QUALITY OF COTTONSEEDS SUBMITTED TO CHEMICAL AND BIOLOGICAL TREATMENTS}

\begin{abstract}
An alternative to chemical treatments is the biological treatment of seeds with bioprotectors. Trichoderma spp. has been considered efficient in the control of fungi and bacteria. This study was carried out with the objective of evaluating the efficiency of the treatments of cottonseeds with the fungicides: carboxin+thiram, carbendazin+thiram and flutolanil, comparing them with T. harzianum, in the seed germination and vigor and in the promotion of seedling growth. The standard germination, emergence in sand and in the field, germination at low temperature, index of germination speed, dry matter and length of the aerial part of the seedlings were evaluated. Seeds treated with $T$. harzianum, carbendazin+thiram and carboxin+thiram showed higher germination and emergence and the first two also resulted in more vigorous seedlings. Seeds treated with carboxin+thiram produced smaller seedlings with lower dry matter.

Index terms: cotton, vigor, Trichoderma harzianum, fungicides.
\end{abstract}

\footnotetext{
${ }^{1}$ Aceito para publicação em 30.07.2003; parte da Dissertação de Mestrado apresentada pelo primeiro autor ao Programa de Pós-graduação em Agricultura Tropical, FAMEV/UFMT.

${ }^{2}$ Eng $^{\text {a }}$ Agr $^{\mathrm{a}}$, Mestre em Agricultura Tropical; FAMEV/UFMT, Av. Fernando Corrêa, s/nº, 78060-900, Cuiabá, MT; e-mail: akemifaria@terra.com.br

${ }^{3}$ Prof $^{\mathrm{a}}$ Adjunto, $\mathrm{Dr}^{\mathrm{a}}$.; Dept $^{\mathrm{o}}$ de Fitotecnia e Fitossanidade, FAMEV/UFMT; e-mail: mariacfa@terra.com.br

${ }^{4}$ Prof. Adjunto, Dr.; Dept ${ }^{0}$ de Fitotecnia e Fitossanidade, FAMEV/UFMT, e-mail: casetari@terra.com.br
}

\section{INTRODUÇÃO}

A semente é um insumo de grande relevância no processo produtivo e sua qualidade é indispensável à implantação de lavouras conduzidas tecnicamente. A qualidade de um lote de sementes compreende uma série de características ou de atributos que determinam o seu valor para a semeadura; den- 
tre os mais relevantes, são considerados os de natureza genética, fisiológica e sanitária (Marcos Filho, 1994).

O clima nos cerrados de Mato Grosso é considerado marginal para o algodoeiro, em função da precipitação excessiva (acima de $1500 \mathrm{~mm}$ anuais). Altitude e umidade elevadas e temperaturas noturnas amenas favorecem a incidência de doenças fúngicas (Freire \& Farias, 1998). O poder germinativo das sementes do algodoeiro pode ser afetado por condições ambientais, bem como pela manifestação de fungos patogênicos, devido à exposição do fruto no campo (Rodrigues Filho et al., 1979), existindo uma relação entre a quantidade e qualidade de patógenos presentes na semente e a porcentagem de germinação e vigor do algodoeiro. A desinfestação de sementes de algodoeiro, inoculadas com Colletotrichum gossypii, com $\mathrm{NaOCl} 1 \%$ por um minuto, e imersão em água destilada e esterilizada, proporcionou aumento médio de $54 \%$ no porcentual de germinação e reduziu em 45\% o índice de doença em plântulas (Soave, 1984).

O tratamento de sementes é uma tecnologia recomendada pela pesquisa, diminuindo falhas na germinação, mas os fungicidas atualmente disponíveis para tratamento de sementes de algodoeiro têm mostrado eficiência variável (Goulart, 1998). Além disso, o sistema de produção utilizado na cotonicultura, no Mato Grosso, é considerado de alta tecnologia, com utilização intensiva de insumos agrícolas, havendo a necessidade de diminuir o uso de pesticidas sintéticos. Uma alternativa é o uso de bioprotetores através da microbiolização de sementes.

Trichoderma spp. apresentam amplitude de ação no antagonismo a fungos e bactérias. Esses microrganismos são atóxicos ao homem e aos animais e de custo acessível. Não são produzidos de um recurso natural limitado, mas da multiplicação de microrganismos ilimitados na natureza. Alguns, ainda, podem persistir no solo ou nas plantas, podendo dispensar reaplicações. Além dos já conhecidos efeitos de Trichoderma spp. no controle de patógenos de plantas, certas linhagens podem ter efeito estimulatório direto no crescimento e no florescimento de plantas hortícolas (Baker, 1989).

Sabe-se que a promoção de crescimento de plantas por bactérias e por fungos pode envolver produção de hormônios vegetais, produção de vitaminas ou conversão de materiais a uma forma útil para a planta, absorção e translocação de minerais e controle de patógenos (Melo, 1996).

A adição de Trichoderma spp. a solos autoclavados aumentou a emergência e a matéria seca de plântulas de tomate e de fumo (Windham et al., 1986). Em solos naturais, observou-se que isolados de Trichoderma spp. proporcionaram maior germinação de sementes, emergência e vigor de plântulas de berinjela (Martin-Corder \& Melo, 1997). Mutantes de T. harzianum, selecionados para resistência ao benomyl, comportaram-se como promotores de crescimento, aumentando a matéria seca de plantas de alface transplantadas para substratos inoculados (Cassiolato et al., 1998).

Este trabalho foi conduzido com o objetivo de avaliar a eficiência dos tratamentos de sementes de algodoeiro com os fungicidas carboxin+thiram, carbendazin+thiram e flutolanil, comparando-os com T. harzianum, na germinação, no vigor das sementes e na promoção de crescimento das plântulas.

\section{MATERIAL E MÉTODOS}

Este trabalho foi conduzido nos Laboratórios de Fitopatologia e de Análise de Sementes da FAMEV/UFMT, em janeiro de 2001. Foram utilizadas sementes de algodoeiro, da cultivar ITA 90, deslintadas e naturalmente infectadas, produzidas em Campo Verde, MT, na safra de 1999/2000. O teor inicial de água das sementes foi de 8\%.

Foi avaliada a qualidade fisiológica das sementes submetidas a cinco tratamentos:

1. sementes sem tratamento

2. sementes tratadas com suspensão de conídios de $T$. harzianum

3. sementes tratadas com carboxin+thiram (140g i.a. $+140 \mathrm{~g}$ i.a. $/ 100 \mathrm{~kg})$

4. sementes tratadas com carbendazin+thiram (75g i.a.+175g i.a. $/ 100 \mathrm{~kg})$

5. sementes tratadas com flutolanil (100g i.a./100kg)

O tratamento químico das sementes foi realizado manualmente, colocando-se o(s) fungicida(s) diluído(s) em $5 \mathrm{ml}$ de água, destilada e esterilizada, por quilograma de sementes e, posteriormente, as sementes dentro de um saco plástico e agitando-se até a distribuição homogênea da formulação sobre as sementes.

O isolado de T. harzianum utilizado no tratamento de semente foi obtido de sementes de algodoeiro, cv. ITA 90, produzidas no município de Campo Verde, MT. As culturas de T. harzianum foram desenvolvidas em meio de cultura Batata-Dextrose-Agar (Fernandez, 1993) por sete dias, a $23^{\circ}$ $+/-3^{\circ} \mathrm{C}$ e fotoperíodo de 12 horas.

Para inoculação das sementes com o agente de biocontrole, foi preparada uma suspensão com conídios de $T$. harzianum em água destilada e esterilizada, na qual as sementes ficaram submersas por três minutos. A concentração da solução, determinada em câmara de Neubauer, foi de aproximadamente $10^{6}$ conídios por mililitro. 
Imediatamente após o tratamento, as sementes foram submetidas aos seguintes testes:

Teste de germinação - Foram utilizadas quatro subamostras de 50 sementes, em substrato papel toalha em forma de rolo e mantidas em germinador à temperatura constante de $25^{\circ} \mathrm{C}$. O volume de água utilizado para umedecimento do substrato foi equivalente a 2,5 vezes o peso do papel seco (Brasil, 1992). A avaliação foi realizada aos sete dias, computando-se as plântulas normais.

Massa seca de plântula - As plântulas normais do teste de germinação foram colocadas em sacos de papel, separadas por subamostra e secadas em estufa termoelétrica de circulação forçada, a $80^{\circ} \mathrm{C}$, durante 24 horas. Após esse período, as amostras foram colocadas para esfriar em dessecador e tiveram sua massa determinada em balança com precisão de 0,0001g. O resultado foi expresso em mg/plântula (Nakagawa, 1999).

Germinação à baixa temperatura - Foram utilizadas quatro subamostras de 50 sementes. A semeadura foi feita em papel toalha umedecido com 2,5 vezes o seu peso seco. As sementes foram mantidas em germinador, no escuro, à temperatura constante de $18^{\circ}+/-0,5^{\circ} \mathrm{C}$ por sete dias (Dias \& Alvarenga, 1999). Foram consideradas como plântulas normais, aquelas com comprimento igual ou superior a três centímetros.

Emergência em areia - Foram utilizadas 200 sementes para cada tratamento, divididas em quatro subamostras de 50 sementes, colocadas sobre uma camada uniforme de areia umedecida na profundidade de $1 \mathrm{~cm}$. As bandejas foram mantidas em condições ambientes, com temperatura média de $26,1^{\circ} \mathrm{C}$. O umedecimento foi mantido constante e, após 12 dias, foi avaliada a porcentagem de emergência. Foram consideradas plântulas normais emergidas aquelas com altura maior ou igual a $2,5 \mathrm{~cm}$ e com cotilédones abertos.

Comprimento da parte aérea das plântulas - Foi realizado conjuntamente com o teste de emergência em areia. Foi avaliado o comprimento da parte aérea de plântulas, em centímetros, aos 14 dias após a semeadura.
Índice de velocidade de emergência - Foi avaliado o número de plântulas normais diariamente, à mesma hora, a partir do quarto dia até o décimo segundo dia após a semeadura, em conjunto com o teste de emergência em areia. $\mathrm{O}$ índice de velocidade de emergência foi calculado usando a fórmula proposta por Maguire (1962).

Emergência em campo - Foram utilizadas quatro subamostras 50 sementes por tratamento, cada uma semeada em uma linha de cinco metros. O espaçamento entre linhas foi de $0,90 \mathrm{~cm}$, com 10 plantas por metro linear. A semeadura foi feita manualmente, à profundidade aproximada de quatro centímetros em latossolo vermelho-escuro, com sistema de semeadura direta em palhada de milheto, no esquema de rotação com soja, no município de Campo Verde, MT. A avaliação da emergência foi realizada aos 14 dias após a semeadura. No período de condução do experimento (30/01/2001 a $12 / 02 / 2001$ ), a temperatura média foi $24,2^{\circ} \mathrm{C}$, precipitação total de 110,4mm/dia e umidade relativa média de 79,5\%.

Índice de doença - Foi conduzido em conjunto com a emergência em campo, avaliando-se a severidade do tombamento nas plântulas, no décimo quarto dia após a semeadura. Utilizou-se a escala de notas proposta por Teixeira et al. (1997), substituindo-se notas de zero a três por notas de um a quatro (Tabela 1). Determinou-se o índice médio de doenças em plântulas (I.D.), utilizando a fórmula proposta por McKinney (1923):

$$
I D=\frac{\sum(P n * n)}{P * N}
$$

onde, $\boldsymbol{I D}$ = índice de doença; $\boldsymbol{P n}=$ número de plântulas com determinada nota; $\boldsymbol{n}=$ nota atribuída, segundo a escala de avaliação; $\boldsymbol{P}=$ número de plântulas avaliadas e $\boldsymbol{N}=$ nota máxima, segundo a escala de avaliação.

O experimento foi conduzido no delineamento inteiramente casualizado, com cinco tratamentos e quatro repetições. As variáveis avaliadas foram submetidas à análise de variância e as médias comparadas pelo teste de Tukey, a 5\% de probabilidade.

TABELA 1. Escala de notas para avaliação de tombamento em plântulas de algodoeiro (Teixeira et al., 1997).

\begin{tabular}{cl}
\hline Nota & \multicolumn{1}{c}{ Sintoma } \\
\hline 1 & Ausência de sintomas \\
2 & Plântula com lesão superficial, com até 1,0cm de extensão no hipocótilo \\
3 & Plântula com lesão(ões) deprimida(s), acima de 2,0cm de extensão no hipocótilo \\
4 & Plântula em colapso total (morte) \\
\hline
\end{tabular}




\section{RESULTADOS E DISCUSSÃO}

As sementes submetidas aos diversos tratamentos não tiveram o mesmo desempenho $(\mathrm{P}<0,01)$ nos testes de germinação e de vigor avaliados pela germinação à baixa temperatura, pelo índice de velocidade de emergência, pela massa seca e pelo comprimento da parte aérea das plântulas. Não foi observado efeito significativo dos tratamentos nos testes de emergência em areia, emergência em campo e índice de doença.

Os resultados de germinação e vigor de sementes tratadas com diferentes produtos estão nas Figuras 1 a 5 . As sementes submetidas aos tratamentos com T. harzianum, carboxin+thiram e carbendazin+thiram apresentaram porcentagem de germinação estatisticamente superior à testemunha e essa foi semelhante ao flutolanil (Figura 1).

No teste de germinação à baixa temperatura, as sementes tratadas com carboxin+thiram e carbendazin+thiram foram superiores à testemunha, porém não diferiram das tratadas com T. harzianum e flutolanil (Figura 1).

Machado et al. (1999) verificaram que o tratamento químico de sementes de algodoeiro com as misturas de carbendazin+thiram (75g i.a.+175g i.a./100kg de sementes) e carboxin+thiram (100g i.a.+100g i.a./ 100kg de sementes) reduziu a população inicial de fungos causadores de tombamento do algodoeiro, aumentando a emergência para 82\%, $13 \%$ superior à testemunha. Neste estudo, observou-se que carbendazin+thiram, na mesma dose, e carboxin+thiram, na dose de $140 \mathrm{~g}$ i.a. $+140 \mathrm{~g}$ i.a./ $100 \mathrm{~kg}$ de sementes, aumentaram a germinação padrão para 98,5\% e 96,0\%, respectivamente $20,0 \%$ e $17,5 \%$ superiores à testemunha. Entretanto, na avaliação da emergência em areia e em campo, as sementes tratadas com esses produtos apresentaram desempenho semelhante ao da testemunha, provavelmente, porque as condições de temperatura e umidade em que foram conduzidos os experimentos permitiram a rápida emergência das plântulas, reduzindo o tempo de exposição aos microrganismos causadores do tombamento, além do fato de que antagonistas em solos cultivados reduzem a atividade de patógenos (Figura 1).

Outros autores não encontraram diferenças na emergência de plântulas oriundas de sementes com diferença na qualidade sanitária. Pinto (1998) não detectou diferenças entre sementes de sorgo, tratadas e não tratadas, por meio do teste de emergência em solo esterilizado, mas observou diferenças quando os testes foram conduzidos em solo frio e úmido e em campo, concluindo que os fungos habitantes do solo promoveram redução significativa na germinação das sementes. Yuyama \& Henning (1999) também não encontraram diferença estatística na qualidade fisiológica de sementes de soja tratadas e não tratadas com fungicidas, avaliadas pelo teste de emergência em areia, embora as sementes apresentassem níveis de infecção diferentes.

O índice de doença variou de 32\% a 44\% e não ocorreram diferenças significativas entre os tratamentos, apesar de a porcentagem de infecção das sementes por patógenos ser diferente (Figura 2). Esse índice reflete as condições climáticas por ocasião da semeadura, que foram muito propícias para uma rápida germinação, caracterizadas por temperaturas elevadas e ocorrência de muitas chuvas.

Tanaka (1994) verificou que o índice de infecção por C. gossypii, Fusarium moniliforme e Rhizoctonia solani foi mais elevado em temperaturas consideradas subótimas para a germinação das sementes. Os danos provocados pelo complexo de fungos associados ao tombamento de plântulas são mais intensos em temperaturas subótimas para o crescimento da plântula e resultam da destruição parcial ou total 


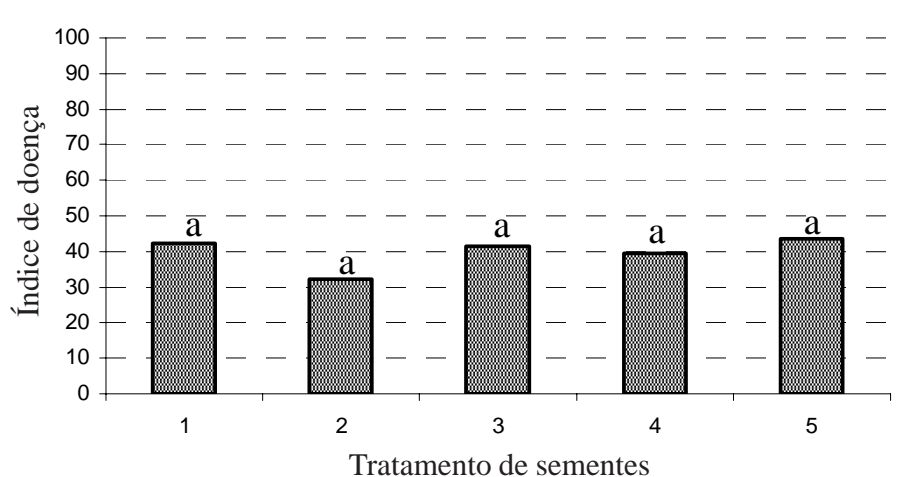

FIG. 2. Índice de doença de sementes sem tratamento (1), tratadas com Trichoderma harzianum (2), carboxin+ thiram (3), carbendazin+thiram (4) e flutolanil (5). Barras com mesma letra não diferem significativamente, pelo teste de Tukey a $5 \%$.

de raízes, cotilédones, hipocótilos e plúmulas (Hunter \& Guinn, 1968; Brown \& McCarter, 1976; Minton \& Garber, 1983). Esse fato tem sido verificado na prática, pela maior intensidade de tombamento quando a semeadura é sucedida por um período chuvoso e queda de temperatura (Tanaka, 1982).

O nível de vigor das sementes, por ocasião da semeadura, também tem efeito pronunciado sobre sua resposta ao tratamento com fungicida. As sementes analisadas apresentavam nível de vigor considerado alto, visto apresentar emergência em campo superior a 70\%, apresentando resposta praticamente nula ao tratamento químico.

Os tratamentos com fungicidas retardaram a emergência, refletindo em menor massa seca das plântulas (Figura 3). Não foi observado efeito estimulante do agente bioprotetor sobre a velocidade de emergência de plântulas, embora am-

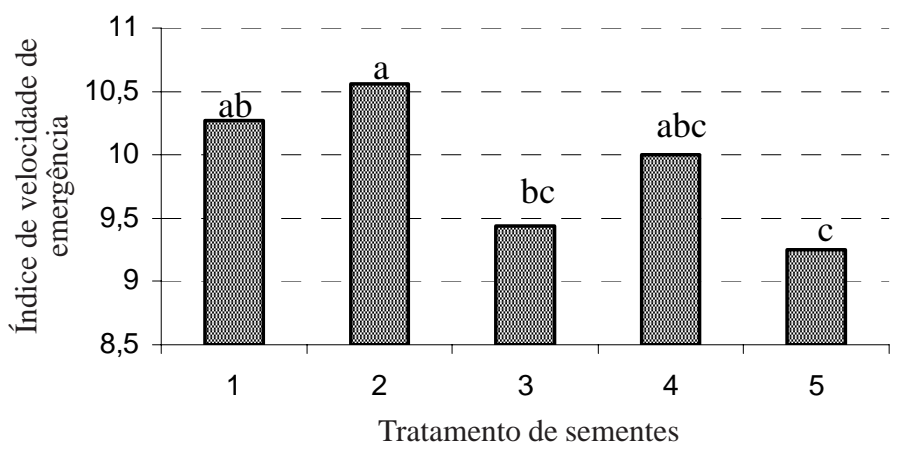

FIG. 3. Índice de velocidade de emergência de sementes sem tratamento (1) e tratadas com Trichoderma harzianum (2), carboxin+thiram (3), carbendazin+ thiram (4) e flutolanil (5). Barras com mesma letra não diferem significativamente, pelo teste de Tukey a $5 \%$. plamente relatado na literatura. Martins \& Melo (1989) observaram o efeito de Trichoderma koningii e Trichoderma viride na germinação e no desenvolvimento de berinjela, com aumentos significativos na precocidade de germinação.

Observou-se efeito negativo do tratamento de sementes com carboxin+thiram, sobre o comprimento da parte aérea e sobre a massa seca das plântulas (Figuras 4 e 5). A dose utilizada (140g i.a. + 140g i.a./100kg) provavelmente interferiu no processo fisiológico da semente, originando plântulas menos vigorosas.

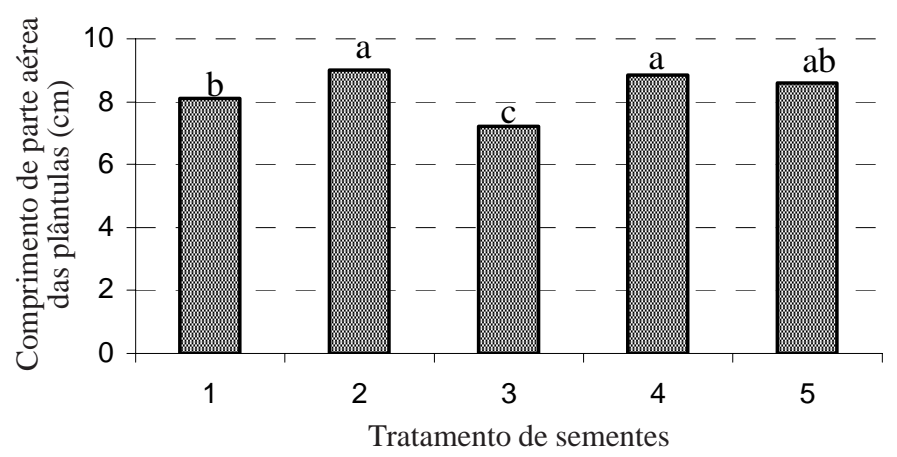

FIG. 4. Comprimento de parte aérea de plântulas oriundas de sementes sem tratamento (1) e tratadas com Trichoderma harzianum (2), carboxin+thiram (3), carbendazin+thiram (4) e flutolanil (5). Barras com mesma letra não diferem significativamente, pelo teste de Tukey a $5 \%$.

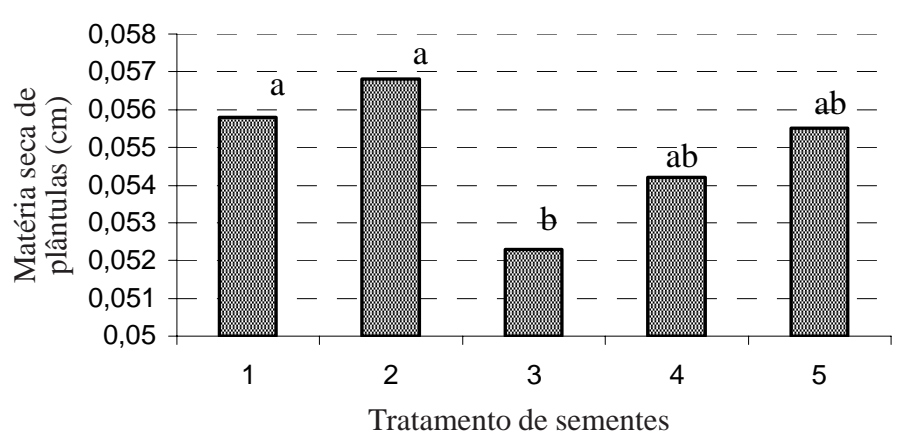

FIG. 5. Matéria seca de plântulas oriundas de sementes sem tratamento (1) e tratadas com Trichoderma harzianum (2), carboxin+thiram (3), carbendazin+ thiram (4) e flutolanil (5). Barras com mesma letra não diferem significativamente, pelo teste de Tukey a $5 \%$.

Os maiores valores de comprimento da parte aérea de plântula foram obtidos nos tratamentos com T. harzianum e carbendazin+thiram, que foram superiores à testemunha, não diferindo do tratamento com flutolanil (Figura 4). Observou- 
se atividade de promoção de crescimento de $T$. harzianum nas plântulas de algodoeiro, em relação à testemunha. Os mecanismos envolvidos no aumento do crescimento e do rendimento, induzidos por espécies de Trichoderma, aparentemente são o controle de patógenos secundários, que diminuem o crescimento e a atividade das raízes, além da produção de fatores estimulantes de crescimento (Baker, 1988; 1991).

O tratamento com carboxin+thiram proporcionou os menores valores de comprimento da parte aérea e da massa seca das plântulas (Figuras 4 e 5). Esses resultados diferem dos encontrados por Schmeling \& Kulka (1969) que relataram que carboxin, quando aplicado nas sementes ou partes aéreas, não apenas controla doenças, mas também estimula o crescimento das plantas. Esses autores relataram que plantas de feijão pulverizadas com suspensão de carboxin a 125 ppm apresentaram altura maior quando comparadas com a testemunha.

Plântulas originadas de sementes tratadas com o bioprotetor apresentaram desempenho semelhante ao carbendazin+thiram, sendo superiores ao carboxin+thiram, nas características velocidade de emergência, massa seca e comprimento de plântula. Ainda, as sementes apresentaram germinação, porcentagem de plântulas infectadas e porcentagem de germinação à baixa temperatura semelhantes aos tratamentos com carboxin+thiram e carbendazin+thiram e superiores aos tratamentos testemunha e flutolanil.

As avaliações realizadas, de maneira geral, reafirmaram a potencialidade de utilização desse antagonista, sugerindo que estudos posteriores nessa direção sejam continuados. Será interessante testar formulações, bem como a seletividade de agroquímicos utilizados nas diversas fases da cultura ao T. harzianum, e a possibilidade de se combinar tratamento químico e biológico, como verificado por Howell et al. (1997), no tratamento de sementes de algodoeiro com metalaxyl $+T$. virens.

\section{CONCLUSÕES}

O tratamento de sementes com Trichoderma harzianum, carboxin+thiram e carbendazin+thiram possibilita melhores germinação e emergência em algodão.

O tratamento de sementes com Trichoderma harzianum e carbendazin+thiram proporciona emergência mais vigorosa de plântulas.

O tratamento com carboxin+thiram possibilita haver plântulas menores, com menor massa seca.

\section{REFERÊNCIAS}

BAKER, R. Trichoderma spp. as plant-growth stimulants. CRC Crit. Review. Biotechnology, v.7, p.97-106, 1988.

BAKER, R. Improved Trichoderma spp. for promoting crop productivity. Trends of Biotechnology, v.7, p.34-38, 1989.

BAKER, R. Diversity in biological control. Crop Protection, v.10, p.85-94, 1991.

BRASIL. Ministério da Agricultura e Reforma Agrária. Regras para análise de sementes. Brasília: SNDA/DNDV/CLAV, 1992. 365p.

BROWN, E.A.; McCARTER, S.M. Effect of seedling disease caused by Rhizoctonia solani on subsequent growth and yield of cotton. Phytopathology, v.66, p.111-115, 1976.

CASSIOLATO, A.M.R.; BAKER, R.; MELO, I.S. de. Promoção de crescimento de plantas de alface por Trichoderma harzianum. Revista de Agricultura, v.71, n.1, p.55-65, 1998.

DIAS, D.C.F.S.; ALVARENGA, E.M. Teste de germinação a baixa temperatura. In: KRZYZANOWSKI, F.C.; VIEIRA, R.D.; FRANÇA NETO, J. de B. Vigor de sementes: conceitos e testes. Londrina: ABRATES, 1999. p.7.1-4.

FERNANDEZ, M.R. Manual para laboratório de fitopatologia. Passo Fundo: EMBRAPA/CNPT, 1993. 128p.

FREIRE, E.C.; FARIAS, F.J.C. Novas tendências e avanços do melhoramento genético do algodoeiro. In: SEMINÁRIO ESTADUAL DO ALGODÃO, 4., Cuiabá, 1998. Anais... Cuiabá: Fundação MT, EMBRAPA, EMPAER-MT, 1998. p.5-20.

GOULART, A.C.P. Tratamento de sementes com fungicidas. In: EMBRAPA. Centro de Pesquisa Agropecuária do Oeste. Algodão: informações técnicas. Dourados: EMBRAPA-CPAO: Campina Grande: EMBRAPA-CNPA, 1998. p.71-84.

HOWELL, C.R. et al. Field control of seedling diseases with Trichoderma virens in combination with fungicide seed treatments. The Journal of Cotton Science, v.1, p.15-20, 1997.

HUNTER, R.E.; GUINN, G. Effect of root temperature on hypocotyls of cotton seedlings as a source of nutrition for Rhizoctonia solani. Phytopathology, v.58, p.981-984, 1968.

MACHADO, A.Q. et al. Controle de patógenos associados às sementes de algodoeiro. In: CONGRESSO BRASILEIRO DE ALGODÃO, 2., 1999, Ribeirão Preto. Anais... Campina Grande: EMBRAPA-CNPA, 1999. p.481-482.

MAGUIRE, J.D. Speeds of germination-aid detection and evaluation for seedling emergence and vigor. Crop Science, v.2, p.176-177, 1962.

MARCOS FILHO, J.; CÍCERO, S.M.; SILVA, W.R. Avaliação da qualidade de sementes. Piracicaba: FEALQ, 1987. 230p.

MARCOS FILHO, J. Utilização de testes de vigor em programas de qualidade de sementes. Informativo ABRATES, Londrina, v.4, n.2, p.33-35, 1994.

MARTIN-CORDER, M.P.P.; MELO, I.S. de. Influência de Trichoderma viride e T. koningii na emergência de plântulas e no vigor de mudas de berinjela. Revista Brasileira de Biologia, v.57, n.1, p.39-45, 1997. 
MARTINS, M.P.; MELO, I.S. Efeito de Trichoderma koningii e T. viride na germinação e no desenvolvimento de berinjela (Solanum melongena L.). Summa Phytopathologica, Jaboticabal, v.15, n.1, p.37. 1989. Resumos.

MCKINNEY, H.H. Influence of soil temperature and moisture on infection of wheat seedling by Helminthosporium sativus. Journal of Agricultural Research, Washington, v.26, n.5, p.195-199, 1923.

MELO, I.S. de. Trichoderma e Gliocladium como bioprotetores de plantas. In: Revisão Anual de Patologia de Plantas, v.4, p.261295, 1996.

MINTON, E.B.; GARBER, R.H. Controlling the seedling disease complex of cotton. Plant Disease, v.67, n.1, p.115-118, 1983.

NAKAGAWA, J. Testes de vigor baseados no desempenho das plântulas. In: KRZYZANOWSKI, F. C.; VIEIRA, R. D.; FRANÇA NETO, J. B. (Ed). Vigor de sementes: conceitos e testes. Londrina: ABRATES, 1999. p.2.1-24.

PINTO, N.F.J. de A. Tratamento de sementes de sorgo visando o controle de fungos do solo e associados às sementes. Summa Phytopathologica, Jaboticabal, v.24, n.1, p.26-29, 1998.

RODRIGUES FILHO, F.S.O. et al. Conservação de sementes de algodoeiro deslintadas por diferentes métodos. Bragantia, v.38, n.11, p.107-113, 1979.
SCHMELING, B. von; KULKA, M. Systemic fungicidal activity of 1,4-oxathiin derivatives. Science, v.152, p.659-660, 1969.

SOAVE, J. Diagnóstico da patologia de sementes de algodoeiro no Brasil. In: SIMPÓSIO BRASILEIRO DE PATOLOGIA DE SEMENTES, 1., Piracicaba, 1984. Anais... Piracicaba: ESALQ, 1984. p.83

TANAKA, M.A.S. Doenças de algodoeiro. Informe Agropecuário, Belo Horizonte, v.8, n.92, p.70-73, 1982.

TANAKA, M.A.S. Patógenos causadores de tombamento do algodoeiro e seus efeitos sobre a germinação das sementes em diferentes temperaturas. Fitopatologia Brasileira, Brasília, v.19, n.1, p.29-33, 1994.

TEIXEIRA, H.; MACHADO, J. da C.; VIEIRA, M. das G.G.C. Avaliação dos efeitos do tratamento químico e biológico na transmissão de Colletotrichum gossypii South. em sementes de algodoeiro (Gossypium hirsutum L.). Ciência e Agrotecnologia, v.21, n.4, p.413-418, 1997.

WINDHAM, M.T.; ELD, Y.; BAKER, R. A mechanism for increased plant growth induced by Trichoderma spp. Phytopathology, v.76, p.518-521, 1986.

YUYAMA, M.M.; HENNING, A.A. Avaliação de fungicidas e suas misturas para o controle de Colletotrichum truncatum em sementes de soja. Informativo ABRATES, Londrina, v.9, n.1/2, p.102, 1999. 